\title{
EFFECT OF INFORMATION REDUNDANGY ON INTEGRATION OF INFORMATION IN PERSONALITY IMPRESSION FORMATION ${ }^{1}$
}

\author{
SUSUMU TAKAHASHI ${ }^{2}$ \\ Aichi University of Education
}

\begin{abstract}
The present study was performed to investigate the effects of information redundancy on the integration of informations as the amount of informations increases. $60 \mathrm{Ss}$ were randomly assigned to 2 experimental conditions: 30 Ss were assigned to High Redundancy condition (Hi-R), and $30 \mathrm{Ss}$ to Low Redundancy condition (Lo-R). The degree of redundancy was manipulated by varying the similarity in meaning of adjectives involved in a set. Each $S$ of both Hi-R and Lo- $\mathrm{R}$ rated their favorableness for persons described by sets of 2, 4, 6 and 8 adjectives along with a 21-point scale. Results obtained tend to provide support for the prediction that an increase in the degree of redundancy among adjectives would decrease the response polarity. Especially, this prediction was strongly supported when stimulus persons were presented by more neutral levels of favorableness of adjectives $\left(\mathrm{M}^{+}\right.$and $\left.\mathrm{M}^{-}\right)$. Furthermore, the set size effect that an increase in the amount of informations increases response polarity did not appear in responses for Hi-R, but was found in Lo-R. The remarkable results were that the effects of differences in redundancy increased with an increase in the amount of informations in responses of $\mathrm{M}^{+}$sets. As on account of failure to interpret these results within the weighted averaging formulation, they were interpreted in light of the discounting hypothesis proposed by Anderson \& Jacobson (1965).
\end{abstract}

Recent experimental research on impression formation has suggested that a numerical impression response toward a stimulus person described by several pieces of informations can be predictable from the weighted averaging model ${ }^{3}$ pro-

${ }^{1}$ A part of this paper was supported by a Grant in Aid for Scientific Researches (\#971020), Ministry of Education.

2 Requests for reprints should be sent to Susumu Takahashi, Department of Psychology, Aichi Lniversity of Education, Igaya-cho, Kariya, Aichi, 448 Japan.

${ }^{3}$ A general formulation of the weighted averaging model can be written as:

$$
R k=\frac{k w A+(1-w) I_{o}}{k w+1-w}
$$

where, $A$ is the scale value of an information, $I_{0}$ is of an initial impression, and $w$ and $1-w$ are weights values for $A$ and $I_{\phi}$, respectively. vided by Anderson (1965) [Anderson, 1967, 1971, 1972a, 1972b, 1972c; Brewer, 1968; Gollob, 1968; Himmelfarb \& Senn, 1969; Kaplan, 1971; Lampel \& Anderson, 1968; Takahashi, 1970; Wyer, 1969, etc.]. In this model, the stimuli are assumed to be averaged with the mean of the weighted values of the stimuli as an overall impression.

However, among those who have tested this formulation, some have paid much attentions to the quantitative properties of informations such as favorableness levels of the stimuli and the amount of informations, and have paid less attentions to their qualitative properties; a interrelationship among informations involved in a set designated by a variety of terms such as trait implication, redundancy, and semantic similarity, or psychological importance 
given to each information. Therefore, there scem to be some limitations to generalize the weighted averaging model in personality impression formation.

Taking into account of the qualitative aspects of informations, Dustin \& Baldwin (1966) offered the redundancy hypothesis, in which it is assumed that whether the stimuli are integrated with an averaging manner, or a summative manner to produce a final impression, depends on the degree of redundancy among informations describing a stimulus person. Mathematically, this model can be written as;

$$
X_{A B}=w S_{A}+w S_{B}-w R_{A B}
$$

Where $X_{A B}$ is the total response to $A B$ combined, $R_{A B}$ denotes the degree of redundancy between $A$ and $B$, and $S_{A}$ and $S_{B}$ are scale values for $A$ and $B$, respectively. In this formulation, a pair of adjectives was defined as redundant if there is a high correlation between two adjectives.

Thus, according to this model, the polarity of response is hypothesized to vary inversely with the degree of rodundancy. Namely, if $R_{A B}$ is positively high, the responses are assumed to be less polarized, and on the other hand, impressions are assumed to be more polarized if $R_{A B}$ was low. Dustin \& Baldwin (1966) obtained the evidences favoring this prediction that impressions based upon pairs of highly redundant informations were less polarized than impressions based upon less redundant pairs. Although this model was strongly supported only when a stimulus person was presented with highly unfavorable adjectives, it is noteworthy to have been indicated the effect of redundancy on the integration of informations in personality impression formation.

Evidences in support for this hypothesis have been provided by Wyer (1968). In his study, the degree of redundancy of an adjective $B$ with a second adjective $A$ was defined in terms of the conditional probability of occurrence of $B$ given by $A$; that is, pair of adjectives was said to be redundant if an adjective $A$ could be inferred from other adjective $B$ with high probability. The noticeable facts obtained were that the effects of differences in redundancy seem to be greater at extreme levels of favorableness of informations than at more neutral levels. Furthermore, Wyer (1970) examined the effects of redundancy, inconsistency, and novelty of informations on the polarity of impressions. Results obtained were support for the hypothesis that the increased redundancy decreases the polarity of total impression.

Contrary to these findings favoring the redundancy theory, Hendrick (1968) found support for the weighted averaging hypothesis using the identical procedure to that of Wyer $(1968,1970)$. He demonstrated that an increase in the degree of redundancy did not decrease the response polarity, and argued that the magnitude of responses for both high and low redundant informations could be predicted from the weighted averaging model.

Thus, more careful considerations must be paid to the effect redundancy among informations in order to examine how several pieces of informations describing a stimulus person are integrated to produce a total impression, because the information redundancy is one of important variables associated with the qualitative properties of informations. Unfortunately, the amount of informations dealt in these studies is not sufficient to test precisely the effect of redundancy on the integration of informations, and hence this inadequacy seems to have brought about somewhat contradictory results as mentioned above.

The primary concerns of this study are to get a further picture how the redundant informations are integrated to produce a final impression as the amount of informations increases, and to explain the effect of redundancy on the polarity of impressions within the weighted averaging theory. That the polarity of impressions increases 
with an increase in the amount of informations involved in a set is shown by wellknown " set-size effect" (Anderson, 1965, 1967; Takahashi, 1970). Thus, more careful examinations should also be given to the amount of informations. The effect of redundancy on the polarity of impressions is possibly clarified more exactly by examining a relationship between the degree of redundancy and the amount of informations.

The decrement in response polarity with an increase in redundancy can be predicted from the weighted averaging model by assuming that an increase in the degree of redundancy would decrease weights given to each information. If this explanation is correct, development in response curves for highly redundant informations against for the less redundants should produce a set of parallel lines; that is, it is hypothesized that there are no significant interactions between the degree of redundancy and the amount of informations in polarization of impressions. A hypothetical relationship between these two variables may be examplified as shown in Fig. 1.

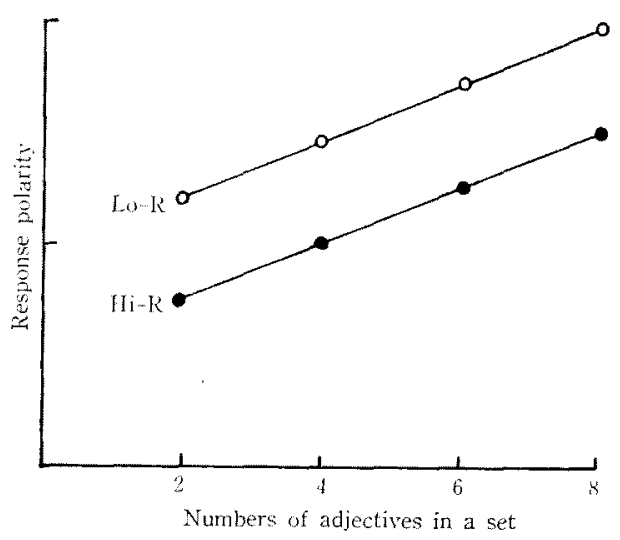

Fic. 1. Hypothetical polarity of response as a function of set size and redundancy.

\section{METHOD}

\section{Suljects}

Subjects of this experiment were 60 female students of Okazaki Training School for Nurse who were fulfilling a course requirement in introductory psychology. As they were randomly assigned to two experimental conditions: $30 \mathrm{Ss}$ were assigned to the High Redundancy condition (Hi-R, in short), and $30 \mathrm{Ss}$ to the Low Redundancy condition (Lo-R, in short).

\section{Preparation of stimulus informations}

The stimulus informations were constructed by simple lists of personality adjectives describing a hypothetical person. Personality adjectives used in this study were selected from the study of Aoki (1971), in which 455 adjectives were rated their social desirability along with a 9-point scale, and they were classified into 10 categories on the basis of the similarity in their semantic connotations. On basis of these normative data, highly favorable adjectives $(\mathrm{H})$, moderately favorables $\left(\mathrm{M}^{+}\right)$, moderately unfavorables $\left(\mathrm{M}^{-}\right)$, and highly unfavorables (L) were selected from each category as stimulus adjectives.

\section{Manipulation of redundancy}

Two levels of information redundancy were manipulated by varying the degree of similarity in semantic connotation among adjectives involved within a set. On the basis of classification by Aoki (1971), the highly redundant informations (Hi-R) were constructed by combining adjectives selected from the same categories, and the less redundant informations (Lo-R) were constructed by combining adjectives selected from the different categories. Therefore, a set of stimulus adjectives is said to be redundant if there is high similarity in meaning among other and is said to be less redundant if the meaning of adjectives are different among other. Examples of sets of adjectives used in this experiment are listed in Table 1.

As there are four levels of stimulus values $(\mathrm{H}$, $\mathrm{M}^{+}, \mathrm{M}^{-}$, and $\mathrm{L}$ ), and 4 levels of the amount 
TABLE 1

Examples of stimulus adjectives used in this experiment and corresponding connotative category

\begin{tabular}{|c|c|c|c|c|c|}
\hline & & \multicolumn{2}{|c|}{ High Redundancy condition } & \multicolumn{2}{|c|}{ Low Redundancy condition } \\
\hline & & Adjective & Category & Adjective & Category \\
\hline \multirow[b]{2}{*}{$H$} & 2 & $\begin{array}{l}\text { genkiga-yoi } \\
\text { kaikatsuna }\end{array}$ & $\begin{array}{c}\text { akarusa } \\
\text {, }\end{array}$ & $\begin{array}{l}\text { ochitsukiga-aru } \\
\text { kuttakuga-nai }\end{array}$ & $\begin{array}{l}\text { atatakasa } \\
\text { akarusa }\end{array}$ \\
\hline & 4 & $\begin{array}{l}\text { shinsetsuna } \\
\text { ninjoga-aru } \\
\text { nagoyakana } \\
\text { hoyoryokuga-aru }\end{array}$ & $\begin{array}{c}\text { atatakasa } \\
\text { " } \\
, \\
,\end{array}$ & $\begin{array}{l}\text { ganbaru } \\
\text { enmanna } \\
\text { hitozukiaiga-yoi } \\
\text { ishiga-tsuyoi }\end{array}$ & $\begin{array}{l}\text { kinbensa } \\
\text { atatakasa } \\
\text { akarusa } \\
\text { hitono-yosa }\end{array}$ \\
\hline \multirow[b]{2}{*}{$\mathrm{L}$} & 2 & $\begin{array}{l}\text { detaramena } \\
\text { horafuki }\end{array}$ & fumajimesa & $\begin{array}{l}\text { sekininkaihi-wo-suru } \\
\text { ikujiga-nai }\end{array}$ & $\begin{array}{l}\text { utsurigi } \\
\text { kino-yowasa }\end{array}$ \\
\hline & 4 & $\begin{array}{l}\text { hito-wo-azakeru } \\
\text { tsugeguchi-wo-suru } \\
\text { kuchigitanai } \\
\text { hito-wo-kenasu }\end{array}$ & $\begin{array}{c}\text { kuchino-warusa } \\
\text { " } \\
\text { " }\end{array}$ & $\begin{array}{l}\text { zanninna } \\
\text { keihakuna } \\
\text { shittobukai } \\
\text { tankyushinga-nai }\end{array}$ & $\begin{array}{l}\text { tsumetasa } \\
\text { keisotsuna } \\
\text { higamipposa } \\
\text { mukiryokusa }\end{array}$ \\
\hline
\end{tabular}

TABLE 2

Types of set used in this experiment and mean $M d$. of desirability for each set

\begin{tabular}{|c|c|c|c|c|c|}
\hline & $\begin{array}{l}\text { ize } \rightarrow \\
s\end{array}$ & 2 & 4 & 6 & 8 \\
\hline \multirow{4}{*}{$\mathrm{Hi}-\mathrm{R}$} & $\mathrm{H}$ & $2 \mathrm{H} \quad(2.90)$ & $4 \mathrm{H} \quad(2.72)$ & $6 \mathrm{H} \quad(2.80)$ & $8 \mathrm{H} \quad(2.82)$ \\
\hline & $\mathrm{M}^{+}$ & $2 \mathrm{M}^{+}(4.05)$ & $4 \mathrm{M}^{+}(4.07)$ & $6 \mathrm{M}^{+}(4.05)$ & $8 \mathrm{M}^{+}(3.90)$ \\
\hline & $\mathbf{M}^{-}$ & $2 \mathrm{M}^{-}(5.80)$ & $4 \mathrm{M}^{-}(5.72)$ & $6 \mathrm{M}^{-}(5.71)$ & $8 \mathrm{M}^{-}(5.75)$ \\
\hline & $\mathrm{L}$ & $2 \mathrm{~L} \quad(7.20)$ & $4 \mathrm{~L} \quad(7.45)$ & $6 \mathrm{~L} \quad(7.33)$ & $8 \mathrm{~L} \quad(7.22)$ \\
\hline \multirow{4}{*}{ Lo-R } & $\mathrm{H}$ & $2 \mathrm{H} \quad(2.85)$ & $4 \mathrm{H} \quad(2.72)$ & $6 \mathrm{H} \quad(2.76)$ & $8 \mathrm{H} \quad(2.77)$ \\
\hline & $\mathrm{M}^{+}$ & $2 \mathrm{M}^{+}(3.95)$ & $4 \mathrm{M}^{+}(3.97)$ & $6 \mathrm{M}^{+}(4.00)$ & $8 \mathrm{M}^{+}(3.91)$ \\
\hline & $\mathbf{M}^{-}$ & $2 \mathrm{M}^{-}(5.70)$ & $4 \mathrm{M}^{-}(5.80)$ & $6 M^{-}(5.78)$ & $8 \mathrm{M}^{-}(5.86)$ \\
\hline & $\mathrm{L}$ & $2 \mathrm{~L} \quad(7.25)$ & $4 \mathrm{~L} \quad(7.20)$ & $6 \mathrm{~L} \quad(7.13)$ & $8 \mathrm{~L} \quad(7.17)$ \\
\hline
\end{tabular}

Note-Scores in parentheses are mean Medians of social desirability measured on a 9-point scale by Aoki (1971), and the greater scores are, the less desirable adjectives are.

TABle 3

Mean favorableness response and $S D$

\begin{tabular}{|c|c|c|c|c|c|c|c|c|c|}
\hline \multirow{2}{*}{\multicolumn{2}{|c|}{$\begin{array}{c}\text { Values } \rightarrow \\
\text { Size } \rightarrow\end{array}$}} & \multicolumn{4}{|c|}{$\mathrm{H}^{-}$adjectives } & \multicolumn{4}{|c|}{$\mathrm{M}^{+}$adjectives } \\
\hline & & 2 & 4 & 6 & 8 & 2 & 4 & 6 & 8 \\
\hline \multirow{2}{*}{$\mathrm{Hi}-\mathrm{R}$} & $\bar{X}$ & 15.76 & 17.90 & 17.63 & 17.96 & 10.67 & 11.96 & 11.80 & 12.03 \\
\hline & $S D$ & 3.52 & 2.71 & 2.31 & 2.67 & 2.92 & 2.54 & 3.24 & 4.52 \\
\hline \multirow{2}{*}{ L.o-R } & $\bar{X}$ & 15.10 & 16.50 & 17.80 & 17.03 & 11.00 & 12.27 & 13.20 & 15.46 \\
\hline & $S D$ & 3.32 & 2.90 & 2.51 & 2.14 & 2.47 & 3.10 & 2.34 & 3.11 \\
\hline
\end{tabular}


of informations $(2,4,6$ and 8$), 16$ types of set were provided for each of two redundancy conditions. Every adjectives does not appear twice in order to avoid an effect of trait replication. Table 2 presents types of set and mean median of desirability ratings for cach of 4 favorableness levels.

\section{Procedure}

Each set was presented at a time by a booklet in which one set was printed per a sheet. To make the stimuli more real, hypothetical initials (e.g., S. T.) identified each of 16 stimulus persons were written on the top of each sheet.

As presenting orders of adjectives in a set and of sets were randomized, each $S$ was given the booklet differed in orders of presentation. Ss were told that several adjectives involved in a set describes a person, and after careful reading they were asked to judge how favorable they feel to each of 16 persons. Ratings of favorableness were made along a 21 point scale, on which three points were identified; 0 (highly unfavorable), 10 (neutral), and 20 (highly favorable). These ratings were made on an another booklet corresponding to the stimulus booklet.

\section{Results}

The mean favorableness ratings for each of 16 types of set are presented in Table 3 , and were analyses as a function of one between variable (two levels of redundancy) and two within-subject variables; four levels of the amount of informations and 4 favorableness levels of the stimulus informations.

The main predictions of this study were two: the first was that responses based on the less redundant informations would be more polarized than those based on the highly redundants regardless of the amount of stimuli, and the second was that the response polarity would increase as a positive function of set size. As favorableness rating was made along an bi-polar numerical scale identifying 10 as a neutral point, directions of response polarity are two ways. That is, the increment in rating scores for favorable adjectives ( $\mathrm{H}$ and $\mathrm{M}^{+}$) indicates an increase in response polarity, while in unfavorable sets $\left(\mathrm{M}^{-}\right.$and $\left.\mathrm{L}\right)$ an increase in response polarity is defined as the decrement in rating scores. To test these predictions, an analysis of variance was applied to responses for favorable sets and to those for unfavorable sets, separately.

In the first place, mean responses for 8 favorable types of set were subjected to an analysis of variance and the result is shown in Table 4. The main effects of the stimulus value (V) and the set size (S) are both significant, while the main effect of redundancy ( $R$ ) did not approach a significance level. Although $R$ was not significant, a significant $\mathrm{R} \times \mathrm{V}$ tends to support in part the prediction that the responses in Lo-R are more polarized than those in Hi-R. As shown in Fig. 2, on which mean responses were plotted as a function of set size and information redundancy, this prediction seems to be

per set as a function of type of set

\begin{tabular}{|cccc|cccc}
\hline & \multicolumn{2}{c|}{ M $^{-}$adjectives } & \multicolumn{4}{|c}{ L adjectives } \\
\hline 2 & 4 & 6 & 8 & 2 & 4 & 6 & 8 \\
\hline 6.33 & 6.20 & 6.00 & 3.87 & 0.93 & 0.63 & 0.93 & 0.76 \\
5.08 & 4.25 & 3.67 & 4.34 & 2.09 & 1.32 & 1.80 & 1.47 \\
\hline 7.53 & 6.23 & 5.33 & 4.00 & 3.07 & 2.23 & 1.93 & 1.16 \\
3.65 & 3.63 & 2.61 & 3.15 & 2.48 & 2.27 & 2.18 & 1.79
\end{tabular}


TABLE 4

The analysis of variance applied to mean favorableness ratings for $\mathrm{H}_{\text {and }} \mathrm{M}^{+}$sets

\begin{tabular}{|c|c|c|c|c|}
\hline Source & $S S$ & $d f$ & $M S$ & $F$ \\
\hline Total & 7509.47 & 479 & & \\
\hline Between $S$ s & 1396.97 & 59 & & \\
\hline Redundancy (R) & 12.68 & 1 & 12.68 & 0.53 \\
\hline Error $(b)$ & 1384.29 & 58 & 23.87 & \\
\hline Within $S \mathrm{~s}$ & 6112.50 & 420 & & \\
\hline Values (V) & 2604.01 & 1 & 2604.10 & $321.48^{* *}$ \\
\hline $\mathrm{R} \times \mathrm{V}$ & 128.13 & 1 & 128.13 & $15.82 * *$ \\
\hline Error $\left(w_{1}\right)$ & 469.86 & 58 & 8.10 & \\
\hline Set-size $(\mathrm{S})$ & 415.22 & 3 & 138.41 & $17.63 * *$ \\
\hline $\mathrm{R} \times \mathrm{S}$ & 8.43 & 3 & 2.81 & 0.35 \\
\hline Error $\left(w_{2}\right)$ & 1366.21 & 174 & 7.85 & \\
\hline$V \times S$ & 39.21 & 3 & 13.07 & 2.33 \\
\hline $\mathbf{R} \times \mathbf{V} \times \mathbf{S}$ & 109.26 & 3 & 36.42 & $6.48 * *$ \\
\hline Error $\left(w_{3}\right)$ & 972.17 & 174 & 5.62 & \\
\hline
\end{tabular}

supported strongly in responses for $\mathrm{M}^{+}$ adjectives. Furthermore, differences in response polarity between $\mathrm{Hi}-\mathrm{R}$ and Lo-R in $\mathrm{M}^{+}$sets tend to increase with an increase in the amount of informations.

Then, response differences between two redundant informations at each level of set size were compared to test the effects of redundancy and the amount of informations more precisely. As results of $t$-tests,

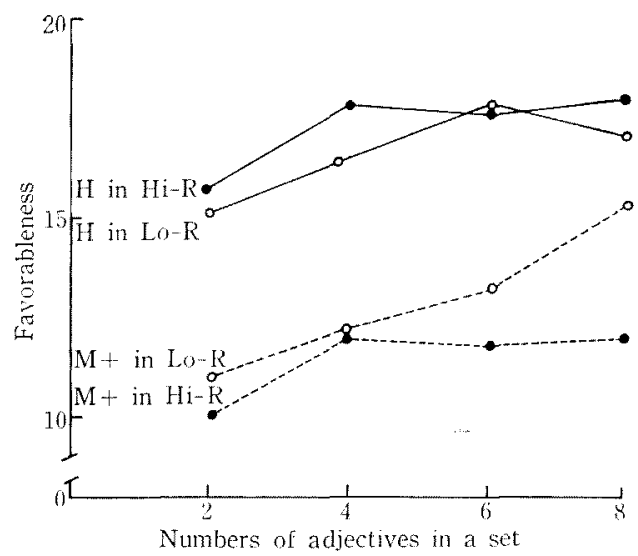

FiG. 2. Mean favorableness responses of $\mathrm{H}$ and $\mathrm{M}^{+}$sets as a function of sets size and redundancy. significant response differences were found in between Hi-R and Lo- R at set of six adjectives $(t=1.96, .50<p<.10)$, and at set of 8 adjectives $(t=3.36, p<.01)$ in $\mathrm{M}^{+}$ sets. In $\mathrm{H}$ sets, however, there is no significant differences in response polarity between two redundancy conditions at any levels of set size. These results are somewhat inconsistent with those reported by Wyer (1968) that the effects of differences in redundancy were greater at extreme levels of favorableness of informations than at more neutral levels.

The rates of increment in response polarity as a function of set size were analysed to determine whether the set size effect appears in general, or not. As the results of every comparisons between each two levels of set sizes, shown in Table 5, responses of $\mathrm{M}^{+}$sets in Lo-R revealed a significant increment in polarity with an increase in the number of adjectives involved in a set, and the increment in response polarity of $\mathrm{H}$ sets which was still not significant in Lo-R was in the direction expected. Contrary to the responses in Lo-R, significant increments in response polarity for both $\mathrm{H}$ and $\mathrm{M}^{+}$sets were not 
TABLE 5

Results of $t$-tests applied to each comparison $\left(\mathrm{H}\right.$ and $\mathrm{M}^{+}$)

\begin{tabular}{|c|c|c|c|c|}
\hline \multirow{2}{*}{$\begin{array}{c}\text { Pairs } \\
\text { compared } \\
\downarrow\end{array}$} & \multicolumn{2}{|c|}{ Lo-R } & \multicolumn{2}{|c|}{ Hi-R } \\
\hline & $\mathrm{H}$ & $\mathrm{M}^{+}$ & $\mathrm{H}$ & $\mathbf{M}^{+}$ \\
\hline $2-4$ & $2.19 * *$ & $1.73^{*}$ & $2.61 * *$ & $1.79^{*}$ \\
\hline $2-6$ & $3.51^{* * *}$ & $3.49 * * *$ & $2.40^{* *}$ & n.s. \\
\hline $2-8$ & $2.64 * *$ & $6.03 * * *$ & n.s. & n.s. \\
\hline $4-6$ & $1.81 *$ & r.s. & n.s. & $n . s$. \\
\hline $4-8$ & n.s. & $3.89 * * *$ & n.s. & $n . s$. \\
\hline $6-8$ & n.s. & $3.14 * *$ & n.s. & $n . s$. \\
\hline$* * * p$ & $\begin{array}{l}1, \quad * * \\
f f=29\end{array}$ & <.05, & * . $05<$ & $<.10$ \\
\hline
\end{tabular}

(both tail, $d f=29$ )

found in $\mathrm{Hi}-\mathrm{R}$, and rather, magnitude of responses seems to be relatively constant independently of an increase in the number of adjectives comprised in a set, implying that the set 'size effect does not necessarily occur in general.

While the results obtained by the above analyses tend to support in part the predictions that an increase in the degree of redundancy would decrease the response polarity, and the set size effect would be shown regardless of information rcdun- dancy, there are some difficulties to interpret the results within the weighted averaging theory.

Nextly, responses for infavorable sets $\left(\mathrm{M}^{-}\right.$and $\left.\mathrm{L}\right)$ were analysed as well as responses for favorable sets. The result of an analysis of variance, shown in Table 6, indicates that main effects of $V$ and $S$ were significant, but the effect of $R$ was not significant. These results are all the same to those obtained in the analyses of favorable sets. Furthermore, a significant interaction was found in only $\mathrm{V} \times \mathrm{S}$, suggesting that in both $\mathrm{Hi}-\mathrm{R}$ and Lo-R responses of $\mathrm{M}^{-}$adjectives were more polarized than those of $L$ adjectives. The mean responses were plotted in Fig. 3 as a function of set size and information redundancy.

Although the effect of redundancy was not significant, the effect of redundancy appeared unexpectedly to be reversal at any levels of set size in responses of $\mathrm{L}$ adjectives, indicating that response polarity of $\mathrm{L}$ sets in Hi-R were greater at every levels of set sizes than those in Lo-R. Significant response differences in $L$ sets between Hi-R and Lo-R were found in a set of two adjectives $(t=3.57, p<.01)$, a set

TABLE 6

The analysis of variance applied to mean favorableness ratings for $\mathrm{M}^{-}$and $\mathrm{L}$ sets

\begin{tabular}{|c|c|c|c|c|}
\hline Source & $S S$ & $d f$ & $M S$ & $F$ \\
\hline Total & 7147.45 & 479 & & \\
\hline Between $S$ s & 1455.83 & 59 & & \\
\hline Redundancy (R) & 63.80 & 1 & 63.80 & 2.66 \\
\hline Error $(b)$ & 1392.03 & 58 & 24.00 & \\
\hline Within $S_{\mathrm{s}}$ & 5691.62 & & & \\
\hline Values (V) & 2146.30 & 1 & 2146.30 & $185.18^{* *}$ \\
\hline $\mathrm{R} \times \mathrm{V}$ & 36.86 & 1 & 36.86 & 3.18 \\
\hline Error $\left(w_{1}\right)$ & 672.72 & 58 & 11.59 & \\
\hline Set-size $(\mathrm{S})$ & 254.86 & 3 & 84.95 & $9.85 * *$ \\
\hline $\mathrm{R} \times \mathrm{S}$ & 42.51 & 3 & 14.17 & 1.64 \\
\hline Error $\left(w_{2}\right)$ & 1501.13 & 174 & 8.62 & \\
\hline$V \times S$ & 71.91 & 3 & 23.97 & $4.36^{*}$ \\
\hline $\mathrm{R} \times \mathrm{V} \times \mathrm{S}$ & 9.44 & 3 & 3.17 & 0.57 \\
\hline Error $\left(w_{3}\right)$ & 955.89 & 174 & 5.49 & \\
\hline
\end{tabular}


of 4 adjectives $(t=3.26, p<.0 \mathrm{I})$ and in a set of 6 adjectives $(l=1.92, .05<p<.10)$. While neither the weighted averaging theory nor the redundancy theory explains this unpredicted finding properly, this fact implies that the effect of redundancy on the polarity of impressions may depends on the favorableness level of the stimulus informations. Thus, a further examination must be required to clarify a relationship between the degree of redundancy and the favorableness level of the stimuli. On the other hand, in $\mathrm{M}^{-}$sets significant differences were not shown in response polarity between two redundancy conditions at any levels of set size. Fig. 3 may suggest a tendency that the polarity of responses varies inversely with the degree of redundancy.

Regarding to the set size effect, the predicted set size effects were found in responses of both $\mathrm{L}$ and $\mathrm{M}^{-}$sets for Lo-R as well as responses of favorable adjectives as being presented in Table 7 . In Hi-R, while significant increments in response polarity for $\mathrm{M}^{-}$sets were revealed in comparisons $2-8,4-8$, and $6-8$, owing to a sudden polarization of responses at sct of 8 adjectives, there were no significant increment in responses of both $\mathrm{M}^{-}$and $\mathrm{L}$ sets independently of an increase in the amount of informations. These results that the set size effects did not appcar in

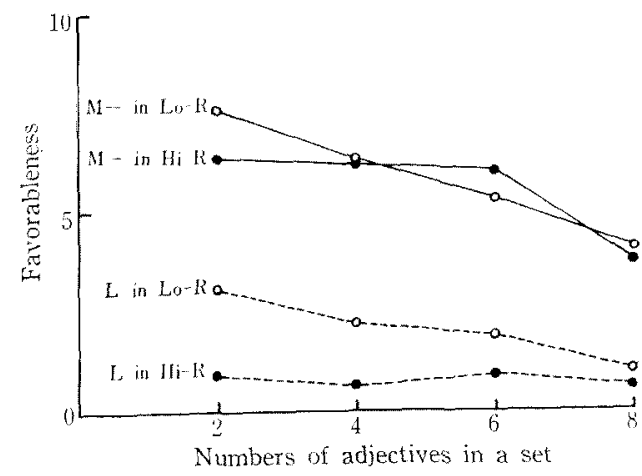

F1G. 3. Mean favorableness responses of $\mathrm{M}^{-}$and $L$ sets as a function of set size and redundancy.
TABLE 7

Results of $t$-tests applied to each comparison ( $\mathrm{L}$ and $\mathrm{M}^{-}$)

\begin{tabular}{|c|c|c|c|c|}
\hline \multirow{2}{*}{$\begin{array}{c}\text { Pairs } \\
\text { compared } \\
\downarrow\end{array}$} & \multicolumn{2}{|c|}{ Lo-R } & \multicolumn{2}{|c|}{$\mathrm{Hi}-\mathrm{R}$} \\
\hline & $\mathrm{M}^{-}$ & $L$ & $\mathbf{M}^{-}$ & $L$ \\
\hline $2-4$ & n.s. & n.s. & n.s. & n.s. \\
\hline $2-6$ & $2.65 * *$ & $1.87^{*}$ & n.s. & n.s. \\
\hline $2-8$ & $3.92 * * *$ & $3.35 * *$ & $1.98^{*}$ & n.s. \\
\hline $4-6$ & n.s. & n.s. & n.s. & n.s. \\
\hline 48 & $2.51 * *$ & $1.98 *$ & $2.06^{* *}$ & n.s. \\
\hline $6-8$ & $1.75^{*}$ & n.s. & $2,01^{* *}$ & $n . s$ \\
\hline
\end{tabular}

responses based upon highly redundant informations are consistent with those obtained by the analyses of responses of favorable sets.

In conclusion, while the effect of redundancy appeared unexpectedly to be reversal in responses of $\mathrm{L}$ sets, impressions of $\mathrm{H}, \mathrm{M}^{+}$and $\mathrm{M}^{-}$sets are consistent in part with the prediction that impressions based upon the highly redundant informations would be less polarized than impressions based upon the less redundant informations. Especially, this prediction seems to be supported strongly when a stimulus person was presented with the more neutral informations. The noteworthy fact found in responses of $\mathrm{M}^{+}$sets is that differences of response polarity between Hi-R and Lo-R tend to increase with an increase in the amount of informations; that is, response curves for Hi-R against for Lo-R produced a set of nonparallel lines.

The set size effect that polarity of responses increases with an increase in the number of adjectives involved in a set were found in responses of all favorableness levels of informations in Lo-R. However, failure to observe a significant set size effect in Hi-R is disappointing and may suggest that the set size effect does not necessarily appear in general as reported by the previous literatures (Anderson, 1965, 
1967; Takahashi, 1970).

\section{Discussion}

Primary concern of this study was on how redundant informations are integrated to produce a final impression as the amount of informations increases. Basing on the weighted averaging model, it was assumed that an increase in information redundancy would be inversely related to the degree of weights given to the stimuli, and consequently, the polarity of response should vary inversely with the degree of redundancy. If this prediction is relevant, response curves as a function of set size for highly redundant informations against for less redundant ones should produce a set of parallel lines as shown in Fig. 1. Further, if the stimuli are integrated with the weighted averaging rule, a set size effect that an increase in the amount of informations increases response polarity would appear even when a stimulus person was presented with highly redundant informations. In summary, this study was designed to explain both effects of information redundancy and of the amount of informations on the response polarity as an output of information integration within the weighted averaging hypothesis.

Although major results obtained did not necessarily clarify the effect of redundancy, the effects of differences in redundancy found in responses of $\mathrm{H}, \mathrm{M}^{+}$, and $\mathrm{M}^{-}$sets tend to support the prediction that impressions based upon $\mathrm{Hi}-\mathrm{R}$ are less polarized than those upon Lo-R, except responses of $\mathrm{L}$ sets in which differences between Hi-R and Lo-R were unexpectedly reversal at any levels of set sizes. This reversal requires that results be treated with some cautions, however, responses of $L$ sets are eliminated in the following discussion. For, it is difficult to look for a plausible explanation of this unpredicated finding.

In a certain way, the partial consistency of the major results obtained in this study with those of Dustin \& Baldwin (1966), and Wyer $(1968,1970)$ seems to provide support for the prediction that response polarity varies inversely with an increase in redundancy. However, the increased response polarity with the decreased information redundancy can not be interpreted by the weighted averaging hypothesis on account of two noticeable findings. The first is that in Hi-R, an increase in the amount of adjectives did not increase the response polarity independently of the favorableness levels of the stimuli; that is, the set size effect predicted from the averaging theory was not found in $\mathrm{Hi}$ $R$. The second was that the effects of differences in redundancy increased with an increase in the amount of adjectives in responses of $\mathrm{M}^{+}$sets.

If the redundancy effect can be predictable from the averaging formulation, these two findings would not be expected. Taking into account of the greater increment in response polarity shown in $\mathrm{Hi}-\mathrm{R}$, the results seem to be rather consistent with the redundancy hypothesis that the less redundant informations are integrated with a summative rule and the highly redundants are integrated with an averaging manner. However, the increment in response polarity shown in Lo- $\mathrm{R}$ is not so large as predicted by the redundancy theory, and rather, it may be predicted from the weighted averaging theory.

Contrary to the averaging and the redundancy theories, another explanations may be considered in regard with the effect of redundancy. One explanation is the "discounting hypothesis" proposed by Anderson \& Jacobson (1965). Applying this hypothesis to the redundancy effect, several adjectives in $\mathrm{Hi}-\mathrm{R}$ are assumed to be discounted to produce a final impression, and consequently responses based upon Hi-R are less polarized than responses based upon Lo-R. If information redundancy brings about discounts of informations, an increase in amount of adjectives 
would tend to increase the number of adjectives discounted. Thus, the effects of differences in redundancy are predicted to increase with an increase in the amount of adjectives involved within a set as a result of discounting of adjectives. While the results seem to be well accounted for by the discounting hypothesis as well as the redundancy hypothesis, the discounting hypothesis is closely related to the averaging model. That is, a discounting of adjectives is considered to be stemmed from differential weighting for each adjective as pointed out by Kaplan (1971) and Hamilton \& Fallot (1974).

Thus far, it was demonstrated that the informations were differentially weighted when informations describing a stimulus person were inconsistent among other, or when the hetrogeneous stimuli (e.g., photo and adjectives) were combined (Anderson \& Jacobson, 1965; Lampel \& Anderson, 1968). For example, when a person is presented with the discrepant informations, among them some are discounted as a result of differential weightings in an integration process $^{4}$ to produce a total impression. Therefore, according to this empirical rationale, as several adjectives in Hi-R might be discounted by unequal weightings, impressions based upon Hi-R might be less polarized than those based upon Lo-R. However, contrary to the differential weighting assumption, in this study responses based upon $\mathrm{Hi}-\mathrm{R}$ were assumed to be less polarized as a result of equal decrement in weighting. That is, in $\mathrm{Hi}-\mathrm{R}$, all adjectives involved in a set were hypothesized to decrease equally weight values given to each adjective. Thus, if the effects of differences in redun-

${ }^{4}$ In the averaging integration theory, two main mathematical models have been considered corresponding to weight values given to informations. In case of equal weighting, the model is defined as the weighted averaging model and is said to the differential weighted averaging model on the occasion of unequal weighting [cf. Anderson, N. H. (1972c)]. dancy can be predicted from the discounting hypothesis, the redundancy effect would be predicted more precisely from the differential weighted averaging model provided by Oden \& Anderson (1971) than from the equal weighted averaging model. Therefore, more careful examinations must be required as to the effect of redundancy on the weighting process in information integration.

\section{ReFERENCES}

Anderson, N. H. 1965 Averaging versus adding as a stimulus combination rule in impression formation. Fournal of Experimental Psychology, 70, 394-400.

ANDERson, N.H. 1967 Averaging model analysis of set size effect in impression formation. Journal of Experimental Psychology, 75, 158-165.

Anderson, N.H. 1971 Integration theory and attitude change. Psychological Review, 78, 171206.

ANDERson, N.H. 1972a Integration theory: a brief survey. CHIP Technical Report No. 24. LaJolla, Calif: Center for Human Information Processing.

ANDERson, N. H. 1972b Algebraic models in perception. CHIP Technical Report No. 30. LaJolla, Calif.: Center for Human Information Processing.

ANDERson, N.H. $1972 \mathrm{c}$ Cognitive algebra: integration theory applied to social attribution. CHIP Technical Report No. 31. LaJolla, Calif.: Center for Human Information Processing.

Anderson, N. H., \& Jacobson, A. 1965 Effect of stimulus inconsistency and discounting instructions in personality impression formation. Journal of Personality and Social Psychology, 2, 531-539.

Aokr, T. 1971 A psycho-lexical study of personality trait words-Selection, classification and desirability ratings of 455 words-. The $3 a p a-$ nese Journal of Psychology, 42, 1-13. (in Japanese with English Summary)

Brewer, N. B. 1968 Averaging versus summation in composite ratings of complex social stimuli. Fournal of Personality and Social Psychology, 8, 20-26.

Dustin, D. S., \& Baldwin, P. W. 1966 Redundancy in impression formation. Journal of 
Personality and Social Psychology, 3, 500-506.

Gollob, H.F. 1968 Impression formation and word combination in sentences. Journal of Personality and Social Psychology, 10, 341-353.

Hamilton, D. L., \& Fallot, R. D. 1974 Information salience as a weighting factor in impression formation. Fournal of Personality and Social Psychology, 30, 444-448.

HENDRICK, C. 1968 Averaging versus summation in impresion formation. Perceptual and Motor Skills, 27, 1295-1302.

Himmelfarb, S., \& SenN, R.J. 1969 Forming impressions of social stimuli: Two tests of an averaging model. Journal of Personality and Social Psychology, 12, 38-51.

Kaplan, M.F. 1971 Context effects in impression formation: the weighted average versus the meaning-change formulation. Fournal of Personality and Social Psychology, 19, 92-99.

Lampel, Anita K., \& Anderson, N.H. 1968 Combining visual and verbal information in an impression formation task. Journal of Personality and Social Psychology, 9, 1-9.

Oden, C. G., \& Anderson, N.H. 1971 Differential weighting in integration theory. Jour nal of Experimental Psychology, 89, 152-161.

TAKAHASHI, S. 1970 Analysis of weighted averaging model on integration of information in personality impression formation. Fapanese Psychological Research, 12, 154-162.

WYER, R.S. 1968 The effects of information redundancy on evaluations of social stimuli. Psychonomic Science, 13, 245-246.

WYER, R.S. 1969 A quantitative comparison of three models of impression formation. Fournal of experimental Research in Personality, 4, 245-246.

Wyer, R.S. 1970 Information redundancy, inconsistency, and novelty and their role in impression formation. Fournal of Experimental Social Psychology, 6, 111-127.

(Received Dec. 26, 1974) 